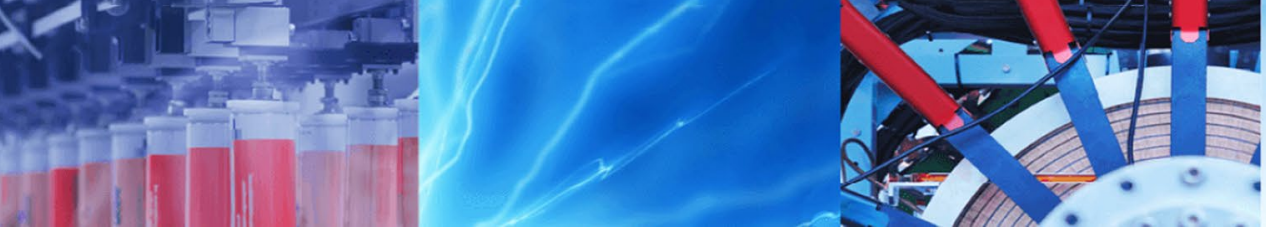

Research Article

\title{
Modelling of integrated processes for the pyrolysis and steam reforming of rice husk (Oryza sativa)
}

\author{
Adewale George Adeniyi $^{1}$ (D) Joshua O. Ighalo $^{1}$ (D) . Fatai A. Aderibigbe
}

(c) Springer Nature Switzerland AG 2019

\begin{abstract}
Thermochemical processes can be used to harness the energetic content of agricultural residues. This study utilises ASPEN Plus v8.8 to develop thermodynamic models for pyrolysis and in-line steam reforming of rice husk (Oryza sativa). The pyrolysis simulation at $500{ }^{\circ} \mathrm{C}$ and $1 \mathrm{~atm}$ gave a product yield of $36.3 \%$ oil, $49.6 \%$ char and $14.1 \%$ gas. Whilst the gas was composed of lighter hydrocarbons, the char was primarily elemental carbon and $\mathrm{SiO}_{2}$. The pyrolysis oil was composed of higher hydrocarbons, an assortment aromatic compounds and pyrolytic water. Optimum parameters for the steam reforming process were $700^{\circ} \mathrm{C}, 1 \mathrm{~atm}$ and a steam-to-gas molar ratio of 7 . The product composition at optimal conditions was $67 \%$ hydrogen gas, $19 \%$ carbon dioxide, $12 \%$ carbon monoxide and $2 \%$ methane. For a theoretical biomass feed of $200 \mathrm{~kg} / \mathrm{h}$ and steam feed of $1400 \mathrm{~kg} / \mathrm{h}$, the synthesis gas flowrate obtained from the process was $204 \mathrm{~kg} / \mathrm{h}$ and the rest were char and condensate water. This has gone a long way to reinforce our idea that the energy content of locally sourced rice (O. sativa) husk can be harnessed via different thermochemical techniques to give good yields of very useful products.
\end{abstract}

Keywords ASPEN Plus · Modelling $\cdot$ Pyrolysis $\cdot$ Steam reforming $\cdot$ Rice husk $\cdot$ Thermodynamics

\section{Introduction}

Rice is a monocotyledonous plant of the genus Oryza. The genus consists of two cultivated species and 21 wild species [1]. The cultivated species Oryza sativa and Oryza glaberrism originated from Asia and Africa, respectively. $O$. sativa has superior yield and milling quality and is commercially grown in 112 countries from all continents. In contrast, $O$. glaberrism is a semi-aquatic plant which is only grown in the West Africa region [1]. Rice (Oryza sativa) is one of the major agricultural products of tropical West Africa in general and Nigeria in particular. The by-product from the milling of rice is the husk. The husk of the plant is currently incinerated by both commercial and local farmers.

Rice husk of course is a very rich cellulosic source for energy recovery processes [2], and it is readily available, especially in West African countries [3]. Rice (Oryza sativa) husk can be converted into useful forms of energy via different novel thermochemical and biochemical conversion techniques. Thermochemical methods include direct combustion, pyrolysis and gasification, whilst biochemical methods include the anaerobic digestion and fermentation processes [1]. Amongst the various biomass thermochemical technologies, pyrolysis presents an interesting opportunity to local stakeholders in harnessing the energetic content of rice (Oryza sativa) husk. Biomass consists of mainly three components: hemicellulose, cellulose and lignin [4]. Each of these three components possesses very different thermal behaviours [5]. The nature and yield of the pyrolysis products are also dependent on the distribution of hemicellulose, cellulose and lignin in the biomass.

The experimental thermochemical conversion of rice (Oryza sativa) husk into useful products has been investigated over the years [6-12], reactor designs inclusive [13, 14]. Alvarez et al. [15] utilised a conical spouted bed reactor

$\triangle$ Joshua O. Ighalo, oshea.ighalo@yahoo.com | ${ }^{1}$ Department of Chemical Engineering, Faculty of Engineering and Technology, University of Ilorin, P. M. B. 1515, llorin, Nigeria.

SN Applied Sciences (2019) 1:841 | https://doi.org/10.1007/s42452-019-0877-6

Received: 7 June 2019 / Accepted: 2 July 2019 / Published online: 9 July 2019 
for bio-oil production from rice husk pyrolysis and obtained a maximum bio-oil yield of $70 \mathrm{wt} \%$ at $450^{\circ} \mathrm{C}$. Tsai et al. [7] investigated the product yield and composition from the pyrolysis of rice husk in a fixed-bed tubular reactor. They observed an oil yield of just above $40 \%$ at the optimal temperature of about $500{ }^{\circ} \mathrm{C}$. Natarajan and Ganapathy [16] also studied rice husk pyrolysis in a fixed-bed reactor and obtained a maximum of about $31 \%$ oil yield at $500^{\circ} \mathrm{C}$. Williams and Nugranad [17] compared products from catalysed and uncatalysed pyrolysis of rice husk and observed that the oils from an uncatalysed process were more homogeneous, of low viscosity and highly oxygenated. In-line steam reforming is unreported yet for rice husk.

Numerous chemical reactions occur during rice husk pyrolysis; therefore, simple stoichiometric reaction equations represent the entire process cannot be practically elucidated. Studies have been conducted on reaction sequences and overall reaction kinetics for biomass pyrolysis in general [18] and rice husk in particular [6]. For numerous biomass samples, kinetics and reaction sequence has been exhaustively examined [19]. Several theoretical in silico models for energy recovery from rice husk have also been developed and validated [20-23] over the years using a variety of approaches.

Researchers have been exploiting ASPEN Plus in modelling different aspects of renewable energy processes. Key research domains have come in the areas of process design, modelling and integration [24-28], feasibility studies [29], thermodynamic analysis [30-32], life cycle assessment [33-35], energy and exergy analysis [36], greenhouse gas assessment [37] and cost analysis [38] amongst other industrial applications and research application [39-42]. Thermodynamic modelling of biomass pyrolysis has previously been conducted for banana residues [43] and sugarcane bagasse [44]. There has not been any report for rice husks. The aim of this study is to utilise ASPEN Plus v8.8 to develop models for the pyrolysis and in-line steam reforming of rice (Oryza sativa) husk to more useful products based on a thermodynamic approach. The models are used to evaluate the product yield and feedstock potential of rice husk for the thermochemical processes. A key advantage of this approach is that it eliminates other extraneous factors present in experimental studies. This helps to paint a true picture of how this process factor affects product yield and portray the true potential of the biomass for thermochemical processing.

\section{Methodology}

The commercial software package ASPEN Plus v8.8 was utilised for the modelling and simulation of the process. ASPEN Plus is a complete integrated solution for process systems engineering [26]. It does not possess any preloaded models but consists of several unit operation blocks. ASPEN Plus can be used to model fast pyrolysis and predict the output of bio-oil, gas and char [43, 44]. It can also be used for steam reforming simulations $[30,45$, 46]. The simulations are based on a minimisation of Gibbs free energy calculation technique. Details of the technique have been explained elsewhere $[47,48]$. The feedstock to be pyrolysed in the simulation is rice (Oryza sativa) husk. Proximate, ultimate and chemical analyses of rice (Oryza sativa) husk were obtained from reported values for West African agricultural residues [49].

\subsection{Model component specification}

The global stream class of the simulation was set as MIXCINC. This informs that there are conventional and non-conventional solids apart from the conventional components. The particle size distribution of the solid component is not required under this selection. Nonconventional components are not present in ASPEN Plus database as they do not have a molecular formula. In the simulation environment, they are specified by the information from their proximate and ultimate analyses. Enthalpy and density are the only properties calculated for nonconventional components, and they are computed by empirical correlations. The specific property methods for enthalpy and density for rice husk were chosen as HCOALGEN method and DGOALIGT method, respectively. Rice (Oryza sativa) husk is a non-conventional material which can be easily modelled in ASPEN Plus v8.8 by specifying proximate and ultimate analyses. Table 1 shows the necessary information required in modelling the biomass in the software.

The conventional components added to the simulation includes saturated aliphatic hydrocarbons $C_{1}-C_{25}$, nitrogen gas, hydrogen sulphide, hydrogen chloride, water, some aromatic compounds and elemental carbon. Water was added to account for the moisture content of the feed. The decomposition products were cellulose, hemicellulose and lignin. Hemicellulose and cellulose are represented in the simulation by their monomers: $\mathrm{C}_{5} \mathrm{H}_{8} \mathrm{O}_{4}$ (xylan) and $\mathrm{C}_{6} \mathrm{H}_{10} \mathrm{O}_{5}$ (xylose-like cellulose monomer), respectively [50]. Lignin was represented in the simulation by a phenyl propane monomer. The nitrogen content of the biomass is taken into account by including pyrrole in the simulation components. The hydrogen sulphide gas accounts for all sulphur contents, whilst hydrogen chloride gas accounts for the chlorine content of the feedstock. Ash was considered to be $\mathrm{SiO}_{2}$ as studies show that above $90 \%$ of the rice husk ash is $\mathrm{SiO}_{2}$ [2]. For the estimation of the physical properties of the conventional components in the simulation, the Peng-Robinson with Boston-Mathias alpha 
Table 1 Proximate, ultimate and chemical analysis of rice (Oryza sativa) husk [49]

\begin{tabular}{ll}
\hline Proximate analysis (wt\% wet basis) & \\
Moisture & 8.59 \\
Fixed carbon & 8.48 \\
Volatile matter & 58.22 \\
Ash & 24.71 \\
Ultimate/elemental analysis (wt\% moisture free) & \\
Carbon & 34.9 \\
Hydrogen & 5.15 \\
Sulphur & 0.64 \\
Oxygen & 59 \\
Nitrogen & 0.31 \\
Chlorine & $<0.01$ \\
Chemical analysis (wt\%) & \\
Cellulose & 37.34 \\
Hemicelluloses & 10.07 \\
Lignin & 41.08 \\
Extractives & 11.51 \\
\hline
\end{tabular}

function equation of state (PR-BM) was used. Alpha is a temperature-dependent parameter that improves the pure component vapour pressure correlation at very high temperatures [33]. For this reason, PR-BM was suitable for the pyrolysis process since relatively high temperatures are involved [43].

\subsection{Reactor model description}

The pyrolysis reaction was modelled in the simulation by a combination of three blocks: the RSTOIC, RYIELD and RGI$\mathrm{BBS}$ reactors. The RSTOIC block is a stoichiometric reactor that utilises stoichiometric equations. This was used to model the drying (evaporation of moisture) of rice (Oryza sativa) husk at the commencement of heating. The RYIELD (yield) reactor carries out the conversion of the dry nonconventional feedstock to conventional simulation components (cellulose, hemicellulose and lignin). The RGIBBS (Gibbs) reactor does the calculation of the final component distribution and phase equilibrium through the minimisation of Gibbs free energy. Both the yield reactor and the Gibbs reactor do not require the specification of stoichiometric equations. Table 2 shows the description of each unit involved in both simulations.

In the development of the simulation model, several assumptions were implemented. Both models prepared with ASPEN Plus v8.8 are steady-state isothermal sequential modular models. In the model for pyrolysis, it was considered that about $95 \%$ of the moisture is evaporated as water vapour. All the sulphur in the biomass is considered as organic sulphur, and it leaves the processes as hydrogen sulphide gas. All chlorine in the processes leaves as hydrogen chloride gas. The ash content of the feedstock was represented as $\mathrm{SiO}_{2}$ alone. All elements take part in the chemical reaction except ash which is considered as inert.

\subsection{Process model description (pyrolysis)}

A steady-state sequential modular model was developed using ASPEN Plus v8.8. In ASPEN Plus, sequencing connotes a block-by-block calculation method where the results of one module serve as the basis for the next. The simulation model is similar to previously developed and validated models albeit with an improvement to account for the initial pre-drying stage $[43,44]$. The simulation ambient temperature and pressure were specified as $25^{\circ} \mathrm{C}$

Table 2 ASPEN Plus unit operations model description

\begin{tabular}{|c|c|c|}
\hline ASPEN Plus ID & Block ID & Description \\
\hline RSTOIC & DRYER & Models the moisture content reduction/drying of the biomass at the initiation of heating \\
\hline RYIELD & DECOMP & $\begin{array}{l}\text { Models the conversion of non-conventional materials (rice husk) to conventional simulation } \\
\text { components (cellulose, hemicellulose and lignin) }\end{array}$ \\
\hline RGIBBS & PYRO & Calculates the pyrolysis products distribution via the minimisation of Gibbs free energy method \\
\hline FLASH2 & SEP1 & Removal of moisture from the pyrolysis vapour stream \\
\hline SSPLIT & SEP2 & Separates the char from the product vapour by specified split ratio \\
\hline HEATER & COOLER & Induces condensation of pyrolysis liquid products by reducing the vapour stream temperature \\
\hline FLASH2 & SEP3 & Separates the pyrolysis oil from non-condensable gases \\
\hline CALCULATOR & WATER & Specifies $90 \%$ moisture removal to the RSTOIC block \\
\hline CALCULATOR & PYROLYSE & $\begin{array}{l}\text { Specifies the RYIELD mass fractions of cellulose, hemicelluloses and lignin based on their pro- } \\
\text { portions in the chemical analysis }\end{array}$ \\
\hline HEATER & HEATER & Raises the temperature of the water feed and converts it to steam \\
\hline RGIBBS & REFORMER & Predicts the steam reforming reactions via the minimisation of Gibbs free energy method \\
\hline FLASH2 & SEP4 & Removes moisture from the reformer vapour stream via condensation \\
\hline
\end{tabular}


and $1 \mathrm{~atm}$, respectively. The rice (Oryza sativa) husk feedstock $(200 \mathrm{~kg} / \mathrm{h})$ and nitrogen purge gas $(0.1 \mathrm{kmol} / \mathrm{hr})$ were fed into the RSTOIC reactor block at ambient conditions, and drying was stipulated to occur at a temperature of $130^{\circ} \mathrm{C}$. The nitrogen helps in the removal of evolving water vapour. In fact, all nitrogen fed into system leaves with the water vapour. About $95 \%$ of the moisture was stipulated to be removed by the dryer by the 'water calculator' block. This was effected by the use of Fortran declarations in the simulation. The RYIELD reactor block carried out the conversion of the non-conventional components to cellulose, hemicellulose and lignin. The split fractions were specified by the 'pyrolyse' calculator block, using the values in the chemical analysis earlier stated. The equations in both calculator blocks were stated using Fortran statements. The process flow diagram (PFD) of the simulation is presented in Fig. 1.

The RGIBBS reactor predicts the final product distribution via the minimisation of Gibbs free energy. The nitrogen gas and $\mathrm{SiO}_{2}$ were specified as inert in the Gibbs reactor. The temperature and pressure of the reactor system are taken as the temperature and pressure of the final reactor block, and they were specified at $500^{\circ} \mathrm{C}$ and atmospheric pressure. The choice of pyrolysis temperature was based on the results of $\mathrm{Ji}$-Lu [8] who observed that for rice husk, optimum pyrolysis temperature was between 420 and $540{ }^{\circ} \mathrm{C}$. The cyclone is used to model the separation of the char from the vapour products. The vapour is then condensed to ambient temperature before the final separation of the non-condensable gases from the oil.

\subsection{Process model description (in-line steam reforming)}

The simulation was adjusted for the steam reforming process. The addition of an in-line steam reforming unit is similar to that previously utilised in a previous work [44]. Conventional components: hydrogen gas, carbon dioxide and carbon monoxide, were added to the simulation. The pre-drying section was removed as water in the pyrolysis oil will favour the reforming reaction. Consequently, the pyrolysis oil obtained in this process will have a high moisture content. The vapour condensation section of the previous simulation was removed, and a steam reformer was introduced instead. Water was pre-heated to a temperature of $120^{\circ} \mathrm{C}$ to obtain a steam feed and then sent into the reformer (Fig. 2).

The vapour products stream was sent directly into the reformer with an inflow of steam going in at a specific steam-to-gas molar ratio (STGR). The reformer is also a Gibbs (RGIBBS) reactor which requires no reaction stoichiometry. Factors such as STGR, reformer temperature and reformer pressure were optimised to give maximum yield of hydrogen from the process. The reformed products are then condensed back to room temperature to separate the excess water from the gaseous products. Response surface methodology (RSM) was used to study the factor interactions and for the determination of optimum parameters for the steam reforming of glycerol. In order for more convenient report, notations in Table 3 are given to the factors/independent variables. For this study, the temperature range considered was 300 and $1100{ }^{\circ} \mathrm{C}$, pressure was between 0.1 and $5 \mathrm{~atm}$, whilst steam-to-gas ratio was between 1 and $12 \mathrm{~mol} / \mathrm{mol}$.

\section{Results and discussion}

\subsection{Pyrolysis results}

After running the simulation, the results obtained at feed rate and pyrolysis temperature of $200 \mathrm{~kg} / \mathrm{h}$ and $500{ }^{\circ} \mathrm{C}$, respectively, are presented in Table 4 . The results demonstrate a decent yield of pyrolysis oil with respect to the other products. From the simulation results, the synthesis gas is composed mainly of $C_{1}-C_{4}$ hydrocarbons with traces of other gases in the simulation as impurities. The char was composed primarily of elemental carbon and $\mathrm{SiO}_{2}$. The pyrolysis oil was composed of the higher hydrocarbons, an assortment aromatic compounds and some pyrolytic water. The moisture content of the oil obtained was $2.02 \%$. This value is quite fantastic because the feedstock is first pre-dried to remove moisture content by $90 \%$. The difference in moisture content is a reason for variations in product composition and yield in experimental works. Ji-Lu [8] summarily observed this also after oil characterisation. It can be seen from Table 5 that simulation results were fairly consistent with experimental works, albeit at different levels. The investigation by Tsai et al. [7] shows a better consistency than that by Ji-Lu [8]. It can be surmised that locally sourced rice (Oryza sativa) husk can be pyrolysed to give decent oil yields. The biomass has been shown to be a promising feedstock for biooil production via the pyrolysis process. The results of the thermodynamic predictions reveal that rice husk is inherently more suitable for the production of char via char optimised processes.

\subsection{In-line steam reforming results}

For the stipulated ranges of STGR, temperature and pressure, a numerical optimisation was carried out to 


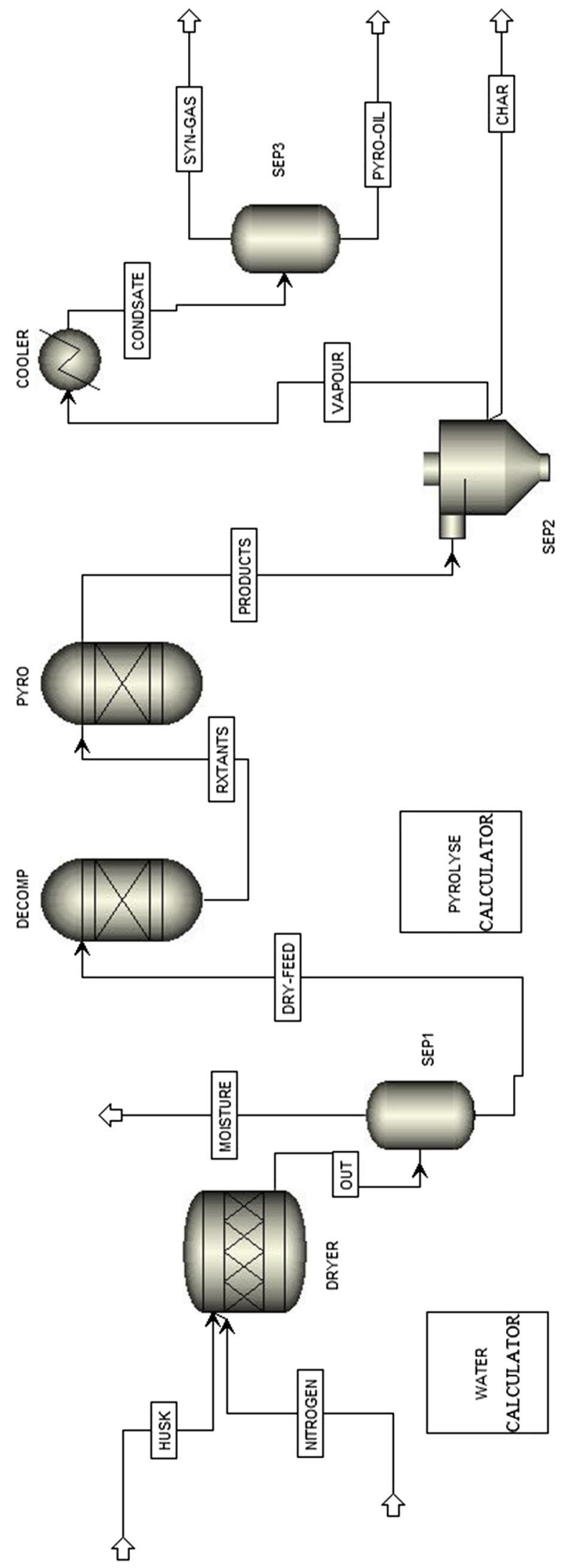

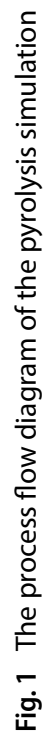




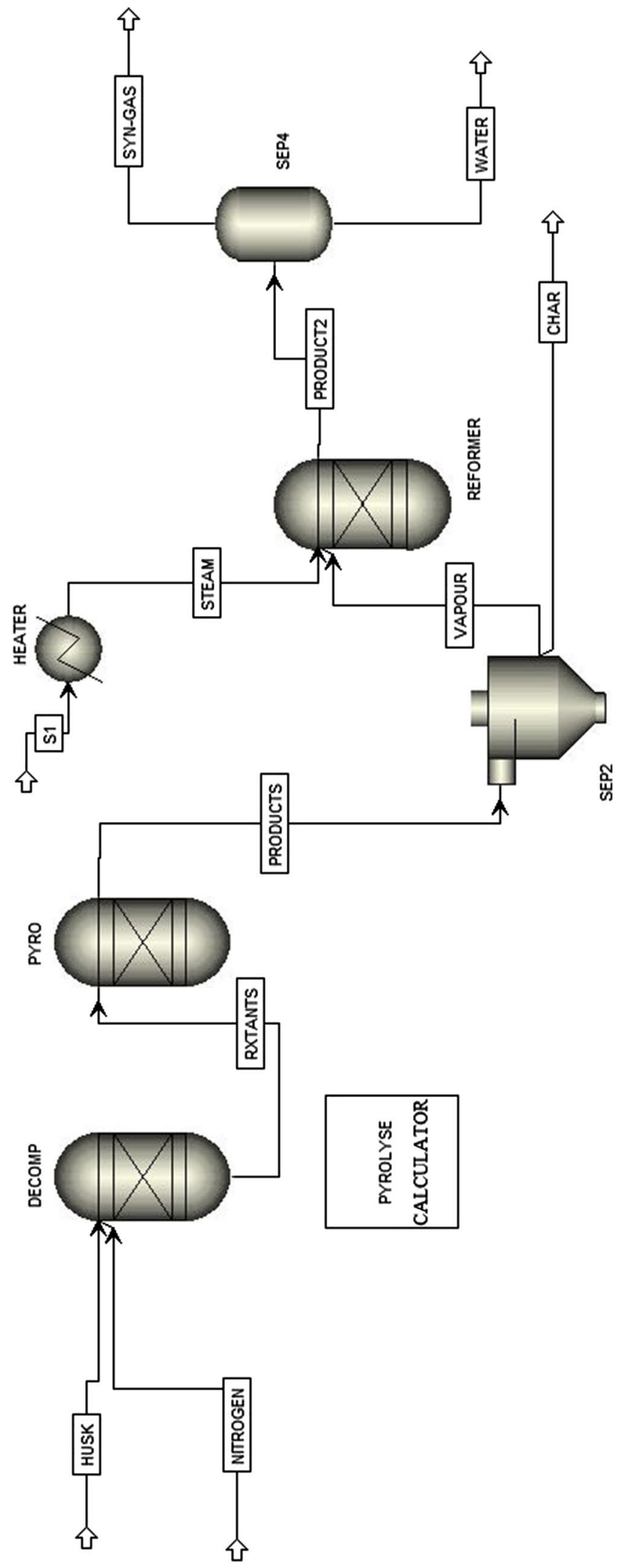

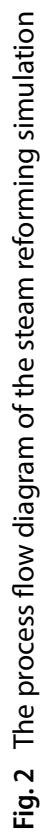


Table 3 Notations of factors/independent variables

\begin{tabular}{ll}
\hline Factor & Unit \\
\hline Reaction temperature & ${ }^{\circ} \mathrm{C}$ \\
Reactor pressure & atm \\
Steam-to-gas ratio (STGR) & $\mathrm{mol} / \mathrm{mol}$ \\
$\mathrm{H}_{2} \%$ Molar composition & $\%$ \\
$\mathrm{CO} \%$ Molar composition & $\%$ \\
$\mathrm{CO}_{2} \%$ Molar composition & $\%$ \\
$\mathrm{CH}_{4} \%$ Molar composition & $\%$ \\
\hline
\end{tabular}

Table 4 Pyrolysis results

\begin{tabular}{ll}
\hline Product & Yield (wt\%) \\
\hline Oil & $36.30 \%$ \\
Char & $49.60 \%$ \\
Gas & $14.10 \%$ \\
\hline
\end{tabular}

Table 5 Validation of results

\begin{tabular}{llll}
\hline & Oil & Char & Gas \\
\hline Current study $\left(500^{\circ} \mathrm{C}\right)$ & $36.30 \%$ & $49.60 \%$ & $14.10 \%$ \\
Tsai et al. [7] $\left(500^{\circ} \mathrm{C}\right)$ & $35.90 \%$ & $47.10 \%$ & $17.00 \%$ \\
Ji-Lu [8] $\left(500^{\circ} \mathrm{C}\right)$ & $53 \%$ & $21 \%$ & $26 \%$ \\
\hline
\end{tabular}

determine the optimum parameters for hydrogen gas production. Optimum parameters were obtained as $897^{\circ} \mathrm{C}, 4.34 \mathrm{~atm}$ and STGR of $7.82 \mathrm{~mol} / \mathrm{mol}$. These values are considered to be purely numerical; hence, a secondary optimisation will be carried out with the simulation itself to get the best possible parameters considering not only hydrogen maximisation, but carbon monoxide maximisation and methane and carbon dioxide minimisation. The above numerical optimisation results will provide the initial basis for examining the simulation.

From the figure above, hydrogen gas production is constant from atmospheric pressure to $3 \mathrm{~atm}$ and then it falls. Methanation is fairly independent of pressure. Between 3 and $5 \mathrm{~atm}$, carbon monoxide production is favoured against carbon dioxide. $\mathrm{CO}$ is usually desired in synthesis gas above $\mathrm{CO}_{2}$ because it is also combustible. However, in considering the process only on the basis of optimising hydrogen generation, $1 \mathrm{~atm}$ remains the optimal pressure for the process. Adeniyi et al. [44] explained that atmospheric pressure is optimal for in-line steam reforming as biomass as lower pressures shifts the chemical equilibrium in favour of the lighter chemical species. Hydrogen is the lightest species in the system; hence, the observed trend in Fig. 3 is validated.

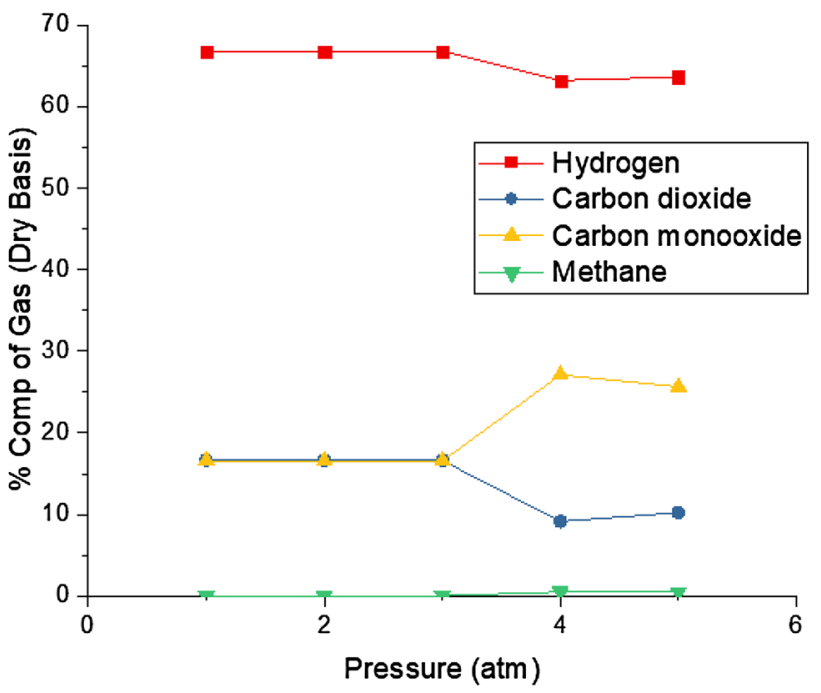

Fig. 3 Gas composition with pressure at $897^{\circ} \mathrm{C}$ and $7.82 \mathrm{~mol} / \mathrm{mol}$ steam-to-gas ratio

Now utilising the optimal pressure alongside the numerical optimal STGR of $7 \mathrm{~mol} / \mathrm{mol}$, we obtain the temperature sensitivity of the synthesis gas produced. Hydrogen production peaks at $700{ }^{\circ} \mathrm{C}$ and starts dropping as the threshold is exceeded. Lower temperatures favour methanation and $\mathrm{CO}_{2}$, whilst higher temperature favours $\mathrm{CO}$ production. Optimal temperature for hydrogen production is $700{ }^{\circ} \mathrm{C}$. The rise in hydrogen production with an increase in temperature is due to the endothermic nature of the steam reforming reaction which is favoured at higher temperatures [30]. The rise in methane production at lower temperatures is due to the exothermic nature of methanation reaction which is favoured at those conditions [30]. The drop in hydrogen production beyond $700^{\circ} \mathrm{C}$ was explained by Adeniyi and Ighalo [48] as competing reaction such as high-temperature thermal cracking of oxygenates, reverse water-gas-shift and coke deposition reactions (Fig. 4).

The above plot in Fig. 5 elucidates gas composition responses to STGR changes at optimal temperature and pressure. Appreciable increase in the hydrogen composition stops at an STGR of about $8 \mathrm{~mol} / \mathrm{mol}$. However, in the simulation a steady but minor increase in hydrogen composition is observed even up to an STGR of $15 \mathrm{~mol} /$ mol. However, in determining the optimal STGR, several points are put in consideration. The combustible methane and CO are favoured at lower STGR compared to the non-combustible $\mathrm{CO}_{2}$. Steam economy is also crucial if the process is to possess any financial appeal to investors. Considering these, optimal STGR is $7 \mathrm{~mol} / \mathrm{mol}$ because beyond that point hydrogen composition does not rise significantly enough considering the fall in the composition of 


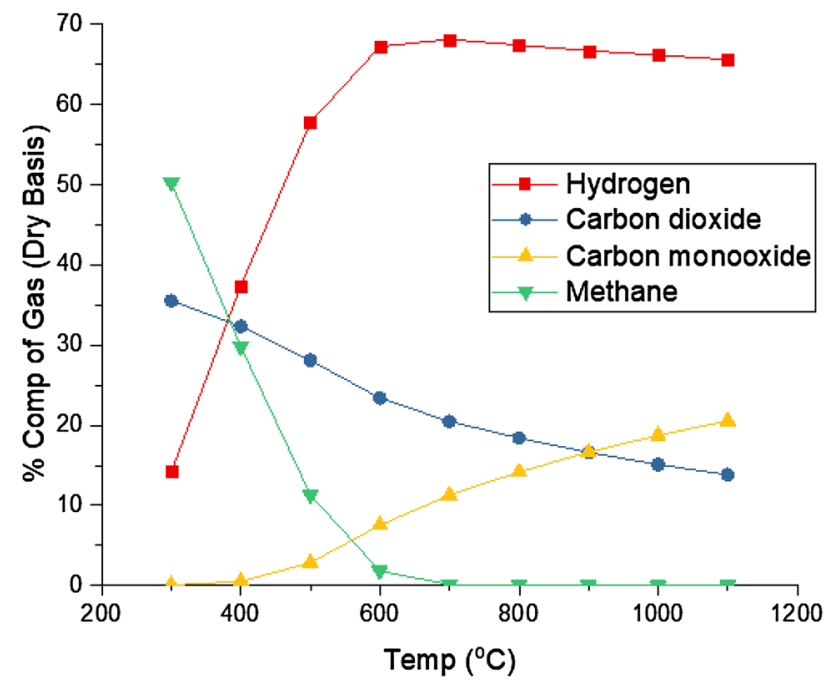

Fig. 4 Gas composition with temperature at $1 \mathrm{~atm}$ and $7.82 \mathrm{~mol} /$ mol steam-to-gas ratio

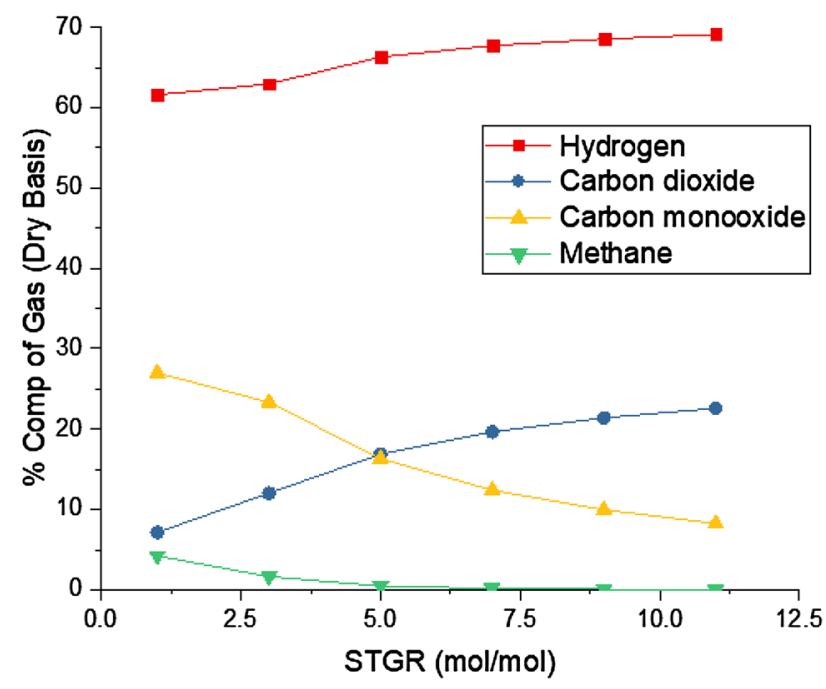

Fig. 5 Gas composition with steam-to-gas ratio at 1 atm and $700{ }^{\circ} \mathrm{C}$

the other combustible products. In summary, optimum parameters are $700{ }^{\circ} \mathrm{C}, 1 \mathrm{~atm}$ and an STGR of $7 \mathrm{~mol} / \mathrm{mol}$ and these will give a product composition of $67 \%$ hydrogen gas, $19 \%$ carbon dioxide, $12 \%$ carbon monoxide and $2 \%$ methane. The synthesis gas flowrate obtained from the process is $204 \mathrm{~kg} / \mathrm{h}$ (for a theoretical $200 \mathrm{~kg} / \mathrm{h}$ biomass and $1400 \mathrm{~kg} / \mathrm{h}$ steam feed rate, respectively) and the rest of the materials are char and condensate water (Fig. 6).

From the above surface plots, we observe that temperature is the most significant factor in the steam reforming of rice (Oryza sativa) husk for hydrogen production. The reforming pressure and STGR demonstrate a far less

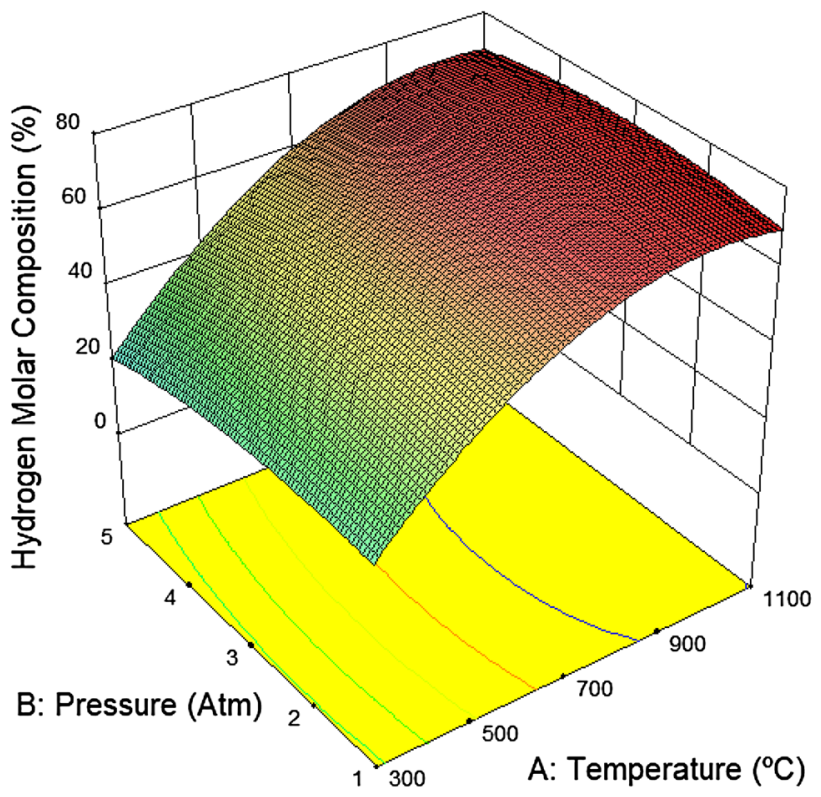

Fig. 6 Surface plot of hydrogen composition response to pressure and temperature

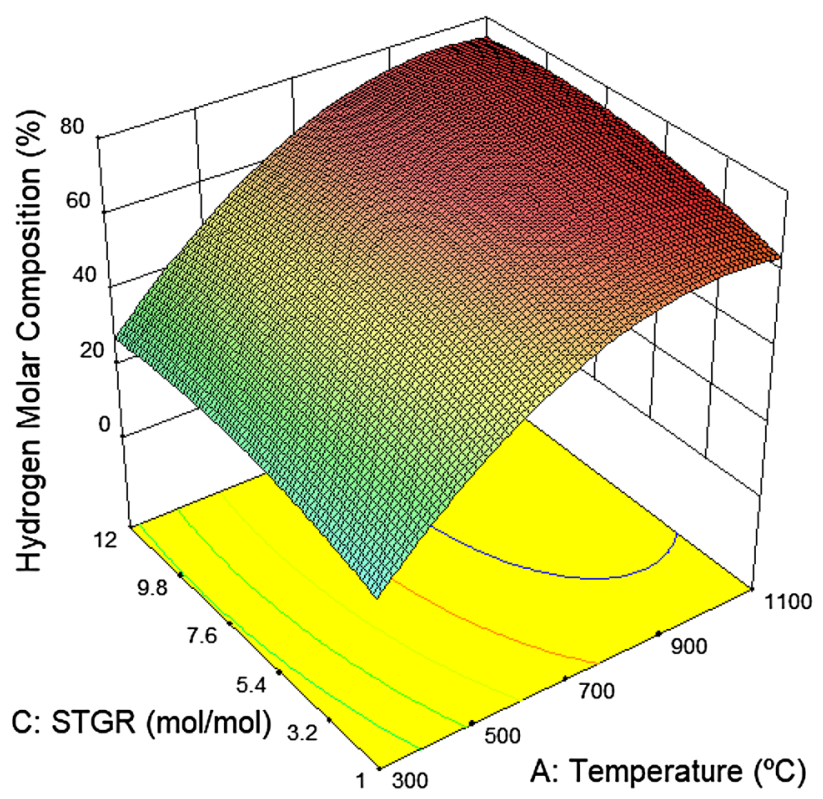

Fig. 7 Surface plot of hydrogen composition response to steam-togas ratio and temperature

significant effect on the composition of hydrogen in the synthesis gas stream. The results of the steam reforming study reveal that rice husk can be harnessed to give an excellent yield of hydrogen via the steam reforming process (Figs. 7, 8). 


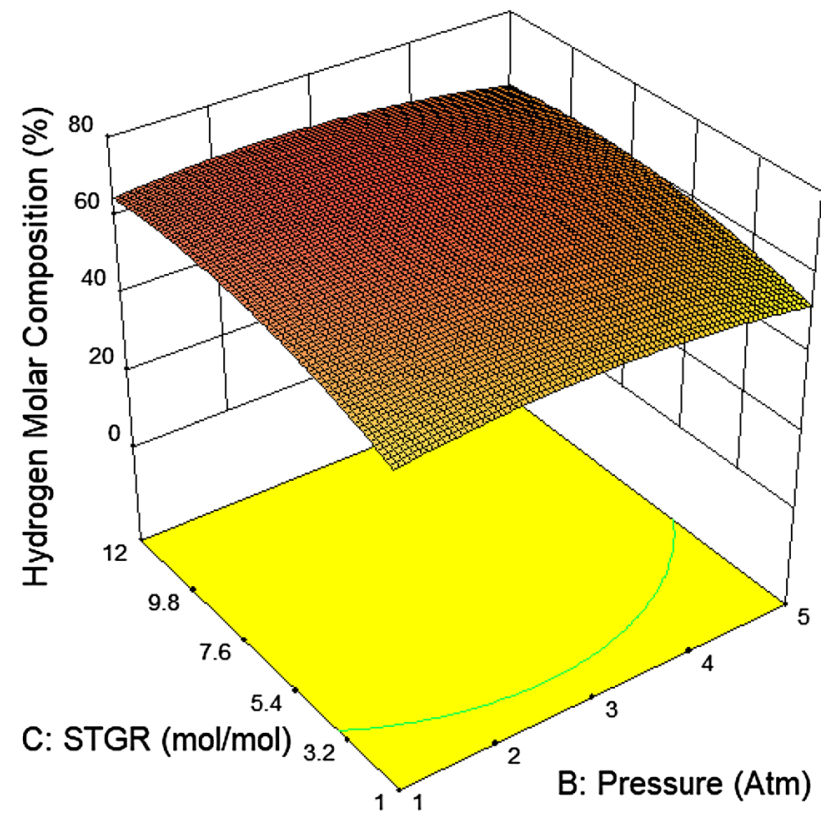

Fig. 8 Surface plot of hydrogen composition response to steam-togas ratio and pressure

\section{Conclusion}

ASPEN Plus v8.8 was used to develop a steady-state model for the pyrolysis of rice (Oryza sativa) husk based on a thermodynamic approach. The simulation pyrolysis conditions were at $500^{\circ} \mathrm{C}$ and atmospheric pressure. After the simulation was run, a yield of $36.3 \%$ oil, $49.6 \%$ char and $14.1 \%$ gas was obtained. The pyrolysis yield was shown to be consistent with experimental studies at similar temperatures. The gas is composed mainly of light hydrocarbons, whilst the char was composed primarily of elemental carbon and as $\mathrm{SiO}_{2}$. The pyrolysis oil was composed of the higher hydrocarbons, an assortment aromatic compounds and 2.02\% pyrolytic water. The results of the thermodynamic predictions reveal that rice husk is inherently more suitable for the production of char via char optimised processes. Optimum parameters for the steam reforming process were $700{ }^{\circ} \mathrm{C}, 1 \mathrm{~atm}$ and an STGR of $7 \mathrm{~mol} / \mathrm{mol}$, and these gave a product composition of $67 \%$ hydrogen gas, $19 \%$ carbon dioxide, $12 \%$ carbon monoxide and $2 \%$ methane. The synthesis gas flowrate obtained from the process was $204 \mathrm{~kg} / \mathrm{h}$. The results of the steam reforming study reveal that rice husk can be harnessed to give an excellent yield of hydrogen via the steam reforming process.

Acknowledgements The Director of the Process Simulation Laboratory Unit of the University of Ilorin is acknowledged.

\section{Compliance with ethical standards}

Conflict of interest No potential conflict of interest was reported by the authors.

\section{References}

1. Lim JS, Manan ZA, Alwi SRW, Hashim H (2012) A review on utilisation of biomass from rice industry as a source of renewable energy. Renew Sustain Energy Rev 16(5):3084-3094. https://doi. org/10.1016/j.rser.2012.02.051

2. Quispe I, Navia R, Kahhat R (2017) Energy potential from rice husk through direct combustion and fast pyrolysis: a review. Waste Manag 59:200-210. https://doi.org/10.1016/j.wasma n.2016.10.001

3. Mansaray K, Ghaly A (1997) Physical and thermochemical properties of rice husk. Energy Sources 19(9):989-1004. https://doi. org/10.1080/00908319708908904

4. QuT, Guo W, Shen L, Xiao J, Zhao K (2011) Experimental study of biomass pyrolysis based on three major components: hemicellulose, cellulose, and lignin. Ind Eng Chem Res 50:10424-10433. https://doi.org/10.1021/ie1025453

5. Gani A, Naruse I (2007) Effect of cellulose and lignin content on pyrolysis and combustion characteristics for several types of biomass. Renew Energy 32(4):649-661. https://doi.org/10.1016/j. renene.2006.02.017

6. Sharma A, Rao TR (1999) Kinetics of pyrolysis of rice husk. Biores Technol 67(1):53-59

7. Tsai W, Lee $M$, Chang Y (2007) Fast pyrolysis of rice husk: product yields and compositions. Biores Technol 98(1):22-28. https://doi. org/10.1016/j.biortech.2005.12.005

8. Ji-Lu Z (2007) Bio-oil from fast pyrolysis of rice husk: yields and related properties and improvement of the pyrolysis system. J Anal Appl Pyrol 80(1):30-35. https://doi.org/10.1016/j. jaap.2006.12.030

9. Mansaray K, Ghaly A, Al-Taweel A, Hamdullahpur F, Ugursal V (1999) Air gasification of rice husk in a dual distributor type fluidized bed gasifier. Biomass Bioenergy 17(4):315-332

10. Loha C, Chattopadhyay H, Chatterjee PK (2011) Thermodynamic analysis of hydrogen rich synthetic gas generation from fluidized bed gasification of rice husk. Energy 36(7):4063-4071. https ://doi.org/10.1016/j.energy.2011.04.042

11. Ganesh A, Grover PD (1992) Combustion and gasification characteristics of rice husk. Fuel 71:889-894

12. Akgün O, Luukkanen J (2012) Extension of rice husk gasification technology for electricity generation in Cambodia. Energy Procedia 14:1244-1249. https://doi.org/10.1016/j. egypro.2011.12.1083

13. Jain AK (2006) Design parameters for a rice husk throatless gasifier reactor. Agricultural Engineering International: CIGR Journal

14. Ramirez J, Martinez J, Petro S (2007) Basic design of a fluidized bed gasifier for rice husk on a pilot scale. Lat Am Appl Res 37(4):299-306

15. Alvarez J, Lopez G, Amutio M, Bilbao J, Olazar M (2014) Bio-oil production from rice husk fast pyrolysis in a conical spouted bed reactor. Fuel 128:162-169. https://doi.org/10.1016/j. fuel.2014.02.074

16. Natarajan E, Ganapathy SE (2009) Pyrolysis of rice husk in a fixed bed reactor. World Acad Sci Eng Technol 56:504-508 
17. Williams PT, Nugranad N (2000) Comparison of products from the pyrolysis and catalytic pyrolysis of rice husks. Energy 25(6):493-513

18. Prakash N, Karunanithi T (2008) Kinetic modeling in biomass pyrolysis-a review. J Appl Sci Res 4(12):1627-1636

19. Gavin W, Stuart D, Emilio R Modeling the impact of biomass particle residence time on fast pyrolysis yield and composition. In: AIChE annual meeting, San Francisco, 2016

20. Mansaray K, Al-Taweel A, Ghaly A, Hamdullahpur F, Ugursal $V$ (2000) Mathematical modeling of a fluidized bed rice husk gasifier: part I-model development. Energy Sources 22(1):83-98. https://doi.org/10.1080/00908310050014243

21. Mansaray K, Ghaly A, Al-Taweel A, Hamdullahpur F, Ugursal $V$ (2000) Mathematical modeling of a fluidized bed rice husk gasifier: part II-model sensitivity. Energy Sources 22(2):167-185. https://doi.org/10.1080/00908310050014144

22. Mansaray K, Ghaly A, Al-Taweel A, Ugursal V, Hamdullahpur F (2000) Mathematical modeling of a fluidized bed rice husk gasifier: part III-model verification. Energy Sources 22(3):281-296. https://doi.org/10.1080/00908310050014063

23. Nikoo MB, Mahinpey N (2008) Simulation of biomass gasification in fluidized bed reactor using ASPEN Plus. Biomass Bioenergy 32(12):1245-1254. https://doi.org/10.1016/j.biomb ioe.2008.02.020

24. Magnusson $\mathrm{H}$ (2005) Process simulation in ASPEN Plus of an integrated ethanol and CHP plant. Dissertation, Umea University, Sweden

25. Ye G, Xie D, Qiao W, Grace JR, Lim CJ (2009) Modeling of fluidized bed membrane reactors for hydrogen production from steam methane reforming with ASPEN Plus. Int J Hydrogen Energy 34(11):4755-4762

26. Ward J, Rasul MG, Bhuiya MMK (2014) Energy recovery from biomass by fast pyrolysis. Procedia Eng 90(90):669-674. https://doi. org/10.1016/j.proeng.2014.11.791

27. Adeniyi AG, Eletta AAO, Ighalo JO (2018) Computer aided modelling of low density polyethylene pyrolysis to produce synthetic fuels. Nigerian Journal of Technology 37(4):945-949. https://doi. org/10.4314/njt.v37i4.12

28. Adeniyi AG, Ighalo JO, Eletta AAO (2018) Process integration and feedstock optimisation of a two-step biodiesel production process from Jatropha curcas using ASPEN Plus. Chem Prod Process Model. https://doi.org/10.1515/cppm-2018-0055

29. Naidoo $S$ (2018) Feasibility study for maize as a feedstock for liquid fuels production based on a simulation developed in ASPEN Plus. MSc Thesis, University of the Witwatersrand, Johannesburg, South Africa

30. Adeniyi AG, Ighalo JO (2018) Study of process factor effects and interactions in synthesis gas production via a simulated model for glycerol steam reforming. Chem Prod Process Model. https ://doi.org/10.1515/cppm-2018-0034

31. Xie H, Yu Q, Wang K, Shi X, Li X (2014) Thermodynamic analysis of hydrogen production from model compounds of bio-oil through steam reforming. Environ Progress Sustain Energy 33(3):1008-1016. https://doi.org/10.1002/ep.11846

32. Goicoechea S, Ehrich H, Arias PL, Kockmann N (2015) Thermodynamic analysis of acetic acid steam reforming for hydrogen production. J Power Sources 279:312-322. https://doi. org/10.1016/j.jpowsour.2015.01.012

33. Altayeb RK (2015) Liquid fuel production from pyrolysis of waste tires: process simulation, exergetic analysis, and life cycle assessment. Masters Thesis, American University of Sharjah, Sharjah, United Arab Emirates
34. Peters JF, Iribarren D, Dufour J (2015) Simulation and life cycle assessment of biofuel production via fast pyrolysis and hydroupgrading. Fuel 139:441-456. https://doi.org/10.1016/j. fuel.2014.09.014

35. Sajid Z, Khan F, Zhang Y (2016) Process simulation and life cycle analysis of biodiesel production. Renew Energy 85:945-952. https://doi.org/10.1016/j.renene.2015.07.046

36. Ofari-Boateng C, Keat TL, JitKang L (2012) Sustainability assessment of microalgal biodiesel production processes: an exergetic analysis approach with ASPEN Plus. Int J Energy 10(4):400-416. https://doi.org/10.1504/IJEX.2012.047510

37. Martinez-Hernandez E, Martinez-Herrera J, Campbell GM, Sadhukhan J (2014) Process integration, energy and GHG emission analyses of Jatropha-based biorefinery systems. Biomass Convers Biorefinery 4(2):105-124. https://doi.org/10.1007/s1339 9-013-0105-3

38. Santana G, Martins P, Da Silva NDL, Batistella C, Maciel Filho R, Maciel MW (2010) Simulation and cost estimate for biodiesel production using castor oil. Chem Eng Res Des 88(5-6):626-632. https://doi.org/10.1016/j.cherd.2009.09.015

39. Adeniyi AG, Adewoye LT, Ighalo JO (2018) Computer aided simulation of the pyrolysis of waste lubricating oil using ASPEN Hysys. J Environ Res Eng Manag 74(2):52-57. https://doi. org/10.5755/j01.erem.74.2.20537

40. Onarheim K, Solantausta Y, Lehto J (2014) Process simulation development of fast pyrolysis of wood using ASPEN Plus. Energy Fuels 29(1):205-217. https://doi.org/10.1021/ef502023y

41. Wang W, Shang Y, Wu J (2011) The lignite coal pyrolysis process simulation based on ASPEN Plus. Chem Ind Eng 28(3):49-53. https://doi.org/10.1080/15567030903226249

42. Yan H, Zhang D (1999) Modeling of a low temperature pyrolysis process using ASPEN Plus. Asia-Pac J Chem Eng 7(5-6):577-591

43. Adeniyi AG, Ighalo JO, Amosa KM (2019) Modelling and simulation of banana (Musa spp.) waste pyrolysis for bio-oil production. Biofuels. https://doi.org/10.1080/17597269.2018.1554949

44. Adeniyi AG, Ighalo JO, Abdulsalam A (2019) Modelling of integrated processes for the recovery of the energetic content of sugarcane bagasse. Biofuels Bioprod Biorefinery. https://doi. org/10.1002/bbb.1998

45. Adeniyi AG, Ighalo JO (2019) Hydrogen production by the steam reforming of waste lubricating oil. Indian Chem Eng. https://doi. org/10.1080/00194506.2019.1605847

46. Adeniyi AG, Ighalo JO, Otoikhian KS (2019) Steam reforming of acetic acid: response surface modelling and study of factor interactions. Chem Prod Process Model. https://doi.org/10.1515/ cppm-2019-0066

47. Adeniyi AG, Otoikhian KS, Ighalo JO (2019) Steam reforming of biomass pyrolysis oil: a review. Int J Chem Reactor Eng. https:// doi.org/10.1515/ijcre-2018-0328

48. Adeniyi AG, Ighalo JO (2019) A review of steam reforming of glycerol. Chem Pap. https://doi.org/10.1007/s11696-019-00840 $-8$

49. Titiloye JO, Bakar MSA, Odetoye TE (2013) Thermochemical characterisation of agricultural wastes from West Africa. Ind Crops Prod 47:199-203. https://doi.org/10.1016/j.indcrop.2013.03.011

50. Peters JF, Iribarren D, Dufour J (2013) Predictive pyrolysis process modelling in ASPEN Plus. In: 21st European biomass conference exhibition

Publisher's Note Springer Nature remains neutral with regard to jurisdictional claims in published maps and institutional affiliations. 